\title{
Reduction Behavior of Low Grade Iron Ore at Reducing Conditions Simulating Different Zones of Blast Furnace
}

\author{
Heba Al-Kelesh ${ }^{a}{ }^{\circledR}$, M. I. Nasr ${ }^{a}$ \\ ${ }^{a}$ Central Metallurgical Research and Development Institute (CMRDI), P. O. Box 87-Helwan, \\ Cairo, 11421, Egypt
}

Received: December 10, 2018; Revised: April 09, 2019; Accepted: June 02, 2019

\begin{abstract}
Representative technological samples for Baharia iron ore are collected from El-Gedida iron ore mines at the western desert of Egypt. Baharia iron ore was fired at $1000^{\circ} \mathrm{C}$ for 3 hours, then the green and fired samples was isothermally reduced by different ratios of $\mathrm{H}_{2} / \mathrm{CO} / \mathrm{CO}_{2} / \mathrm{N}_{2}$ which closely represent the theoretical reduction conditions in different zones of blast furnace. The influence of reduction conditions on the reduction behaviour and the morphology of the reduced samples were investigated. Reduction behavior is arranged as: (cohesive $>$ thermal reserve $>$ top) zones due to reduction power of different zones which affect the microstructure of reduced samples. As a result of slow reaction at top conditions, reducing gas created tracks within the samples which increase porosity. On the other hand at cohesive conditions, grain growth occurred and small spherical grains of fired samples were semi-melted forming sintered clusters. The comparative reduction behavior for green and fired iron ore was investigated. At cohesive zone, the effect of firing can hardly be distinguished. But at thermal reserve and top zones conditions, the reduction rate of fired samples is greater than that for the green samples and that was confirmed by morphological examination of them.
\end{abstract}

Keywords: Reduction, Baharia iron ore, Low grade, Blast furnace.

\section{Introduction}

Ironmaking is the basis of steel manufacture and is considered the most power consuming process in ferrous metallurgy. Different ironmaking technologies have been developed over the years resulting significant changes in iron and steel industry. Generally, ironmaking processes take three forms: blast furnace process $(\mathrm{BF})$, direct reduction and direct smelting processes. Amongst all the ironmaking processes, $\mathrm{BF}$ will continue to be the principal method of ironmaking.

Recently, most of the researches on blast furnace operation are striving to improve both productivity and cost, increase the efficiency of operation as well as decreasing the energy consumption. The production cost depends mainly on the raw materials cost. The most powerful means for reducing energy consumption and increasing productivity in the blast furnace is the improvements in the composition of raw material especially iron ore.

The principal gangue contents in Baharia ore are $\mathrm{SiO}_{2}$ 7-10 \%, MnO 2-4 \% and Alkalies 0.15-0.35\%. Iron exists in the form of hematite $75-78 \%$. Iron ores of El-Gedida are the main source of iron feedstock for the blast furnaces of the Egyptian iron and steel company.

\subsection{Reduction of iron ores}

Many studies were carried out for investigation of reduction behavior of different iron ores by carbon and different reducing gases all over the world ${ }^{1-9}$. Studies on the chemical and physical properties and the reduction behavior in coal of hematite iron ores are investigated ${ }^{2}$.

Baharia iron ore samples were isothermally reduced with a $\mathrm{CO}-\mathrm{CO}_{2}$ gas mixture at $600-1000^{\circ} \mathrm{C}^{3}$. The course of reduction was followed by a weight loss technique. The influence of reducing gas composition and temperature on the reduction kinetics was studied.

Reduction behavior of iron ore pellets with simulated coke oven gas and natural gas was investigated by many researchers $\mathrm{s}^{4-6}$. The highest reduction degree was obtained for the pellets reduced with reformed coke oven gas while the lowest reduction degree was exhibited by original natural gas. On the other hand, the rate of reduction with original coke oven gas was sharply increased at temperature of about $900^{\circ} \mathrm{C}$ to become higher than that of reformed natural gas.

The behavior of wustite prepared from Baharia iron ore sinter during reduction with different ratios of $\mathrm{CO}$ $\mathrm{CO}_{2}-\mathrm{N}_{2}$ gas mixture at $800-1100^{\circ} \mathrm{C}$ was investigated ${ }^{10}$. 
The influence of temperature and gas composition on the reduction behaviour and the morphology was investigated. The apparent activation energy values were calculated and correlated with the gas-solid reaction formulations to elucidate the corresponding mechanism at both early and final reduction stages. The reduction rate of pure wustite samples is most likely controlled by the combined effect of chemical reaction and gaseous diffusion mechanisms while the reduction rate of wustite from iron ore sinter is most likely controlled by interfacial chemical reaction mechanism.

The present study aims at investigation of reduction behavior of green and fired Baharia iron ore isothermally at reduction conditions simulating different zones in the blast furnace.

\section{Experimental Work}

Representative technological samples from Baharia iron ore are collected from El-Gedida. For reduction of iron ore, the thermobalance used for monitoring weight change of samples consists of vertically tube furnace wound by kanthal wire designed for attaining a maximum temperature of $1200^{\circ} \mathrm{C}$. The temperature was automatically measured and controlled by a $\mathrm{Ni} / \mathrm{Ni}-\mathrm{Cr}$ thermocouple connected to a temperature controller with indicator (Heraus $\mathrm{GmbH}-1200^{\circ} \mathrm{C}$ ). The reaction tube, which is a sintered alumina tube of $60 \mathrm{~cm}$ long and $4.2 \mathrm{~cm}$ inner diameter, is fitted inside the furnace.

Before starting each reduction experiment, glass towers are regularly refilled with fresh silica gel and soda lime then carbon monoxide gas was allowed to pass over these towers to purify it from carbon dioxide and water vapor. Silica gel towers were used for drying the carbon dioxide, hydrogen and nitrogen gases. The flows of purified gases were measured by digital flow meters (SIERRA, Smart-Trak Series 100). The reduction processes were carried out at different temperatures to simulate different zones in the blast furnace.

For each reduction experiment, the furnace was heated up to the required reduction temperature, and then the sample was weighed and placed in the basket. The sample was then gradually introduced into the furnace so as to avoid thermal shock cracking and positioned in the middle of the furnace constant hot zone. First, nitrogen gas at a flow rate of 1 liter/min was introduced. Then after a sample soaking for 10 minutes at the reduction temperature, the reducing gas mixture at a total flow rate of 1 liter/min was introduced. The weight loss resulted from oxygen removal from the samples was intervally recorded with time. At the end of the experiment, the basket with the reduced samples was removed and dropped by releasing its suspension wire from the balance, into a conical flask containing acetone to prevent pyrophority of the reduced sample.
Iron ore was compacted into briquettes of $2 \mathrm{gm}$ weight, $10 \mathrm{~mm}$ diameter and $7 \mathrm{~mm}$ height. The prepared briquettes were isothermally reduced by different ratios of $\mathrm{H}_{2} / \mathrm{CO}$ / $\mathrm{CO}_{2} / \mathrm{N}_{2}$ (Table 1) which closely represent the theoretical composition of gas mixture at different parts of the blast furnace namely cohesive zone, thermal reserve zone and top zone. Mathematical model of blast furnace based on mass and heat balance and the chemical analysis of top gases is used to determine the gas mixture at different furnace zones ${ }^{11,12}$.

Prepared briquettes were fired at $1000^{\circ} \mathrm{C}$ for 3 hours, and then isothermally reduced at the reduction conditions shown in table 1. Finally, the reduction extent is calculated ${ }^{13-15}$. As reference experiment, sample is reduced at $1100^{\circ} \mathrm{C}$ by hydrogen gas (flow rate $=1 \mathrm{l} / \mathrm{min}$.) to calculate the total oxygen content $\left(\mathrm{w}_{\mathrm{o}}\right)$,

$$
\mathrm{w}_{\mathrm{o}}=\mathrm{w}_{\mathrm{i}}-\mathrm{w}_{\mathrm{f}}
$$

Reduction extent at time $t\left(R_{t}\right)$ is calculated as:

$$
\mathrm{R}_{\mathrm{t}}=\left(\left(\mathrm{w}_{\mathrm{i}}-\mathrm{w}_{\mathrm{t}}\right) / \mathrm{w}_{\mathrm{o}}\right) \times 100
$$

where,

$$
\mathrm{w}_{\mathrm{i}}=\text { weight at zero time, } \mathrm{w}_{\mathrm{t}}=\text { weight at time } \mathrm{t}
$$

Reflected light microscope (RLM) and Field emission scanning electron microscope (FESEM) were used to examine the microstructure of the fired as well completely reduced samples. The effect of different compositions of gas mixture on the reduction behavior and morphological changes of iron ore at different temperatures was investigated.

\section{Results and Discussion}

\subsection{Characterization of green samples by X-ray diffraction (XRD) and $X$-ray fluorescence (XRF)}

X-ray diffraction analysis was carried out for the samples at room temperature and diffraction patterns were obtained by means of a chart recording Philips PW (1790) X-ray diffractometer using copper $(\mathrm{K} \alpha)$ radiation. The instrument was properly calibrated and adjusted with respect to the $\mathrm{X}$-ray source. A high voltage of $40 \mathrm{kV}$ and anode current of $30 \mathrm{~mA}$ were chosen. The connected Geiger Muller tube detector was adjusted to the order of one degree/cm for identification purposes. 
Table 1. The theoretical composition of gas mixture and temperature at different parts of blast furnace

\begin{tabular}{cccccc}
\hline \multicolumn{7}{c}{ Gas composition, vol\% } & Different zones in blast furnace & Temp., ${ }^{\circ} \mathbf{C}$ \\
\hline $\mathbf{H}_{2}$ & $\mathbf{C O}$ & $\mathbf{C O}_{2}$ & $\mathbf{N}_{2}$ & Cohesive zone & 1100 \\
8.1 & 45 & 0 & 55 & Thermal reserve zone & 927 \\
5.1 & 40 & 5 & 55 & Top zone & 700 \\
4.1 & 35 & 10 & 55 & & \\
\hline
\end{tabular}

The interplanar spacing (d) was derived from the observed Braggs law:

$$
2 d \sin \theta=n \lambda \quad \text { where } n=1
$$

Where $\lambda=1.5405$, is the wavelength associated with $\mathrm{Cu}$ $\mathrm{K} \alpha$ radiation used and $\theta$ is the scattering angle. The relative intensity $\left(\mathrm{I} / \mathrm{I}_{\mathrm{o}}\right)$ was calculated for all lines in the obtained diffraction patterns. It can be noticed that the sample mainly contains geothite and hematite phases with total iron percent $55.3 \%$ beside some impurities such as quartz and Mn-Fe silicate composite as shown in Fig. 1 and its complete chemical analysis is shown in Table 2.

\subsection{Studying the reduction behavior of green samples}

The isothermal reduction curves of iron ore briquettes reduced by different compositions of gas mixture and temperature representing different parts of the blast furnace are given in Fig. 2. For each single reduction curve, the rate of reduction was highest at the early stages and decreased as reduction proceeds till the end of reduction. The rate of reduction increases by descending from top zone condition to cohesive zone condition.

Reduction of green samples at top zone and thermal reserve zone conditions was not complete and stopped at about $40 \%$ and $80 \%$ reduction extent respectively. This behavior is due to the reduction power of different zones arranges as follow: cohesive zone $>$ thermal reserve zone $>$ top zone as shown in table 1 . The microstructure of reduced samples was examined by reflected light microscope as shown in Fig. 3(a, b). It was observed that samples reduced at top zone reduction conditions have relatively low porosity with few macro and micro-pores due to lower reduction rate and fine iron grains formed with unreacted iron oxide in homogenous way. On the other hand samples reduced at thermal reserve zone reduction conditions have relatively more porous structure with many macro and micro-pores in its structure with many and large iron grains.

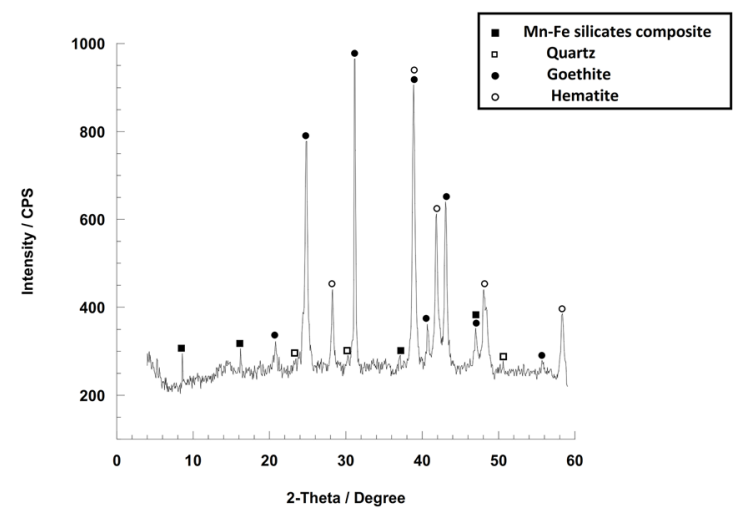

Figure 1. XRD patterns of Baharia iron ore.

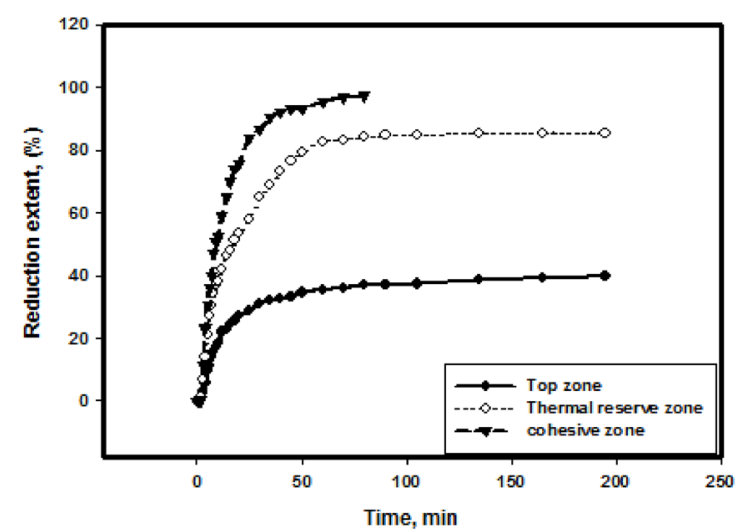

Figure 2. Reduction behavior of iron ore in different zones of blast furnace.

The microstructure of samples reduced at top zone conditions compared with green samples is shown in Fig $4(\mathrm{a}, \mathrm{b})$ respectively. For the green sample, grains with different sizes are featured with relatively few micro- and macro-pores. After reduction, smaller grains appeared in the structure, grain boundaries started to vanish and grains start to be agglomerated creating larger macro-pores.

Table 2. Chemical analysis of Baharia iron ore

\begin{tabular}{|c|c|c|c|c|c|c|c|c|c|c|c|c|c|}
\hline Oxides & $\mathrm{SiO}_{2}$ & $\mathrm{Al}_{2} \mathrm{O}_{3}$ & $\mathrm{Fe}_{2} \mathrm{O}_{3}$ & $\mathrm{CaO}$ & $\mathbf{K}_{2} \mathbf{O}$ & MnO & $\mathrm{Na}_{2} \mathrm{O}$ & MgO & $\mathrm{SO}_{3}$ & $\mathrm{TiO}_{2}$ & $\mathbf{P}_{2} \mathbf{O}_{5}$ & $\mathrm{BaO}$ & LOI \\
\hline Wt $\%$ & 7.98 & 1.55 & 74.72 & 0.25 & 0.29 & 2.95 & 0.19 & 0.54 & 0.98 & 0.12 & 0.42 & 1.35 & 7.96 \\
\hline \multicolumn{14}{|l|}{ Baharia } \\
\hline iron ore & & & & & & & & & & & & & \\
\hline
\end{tabular}



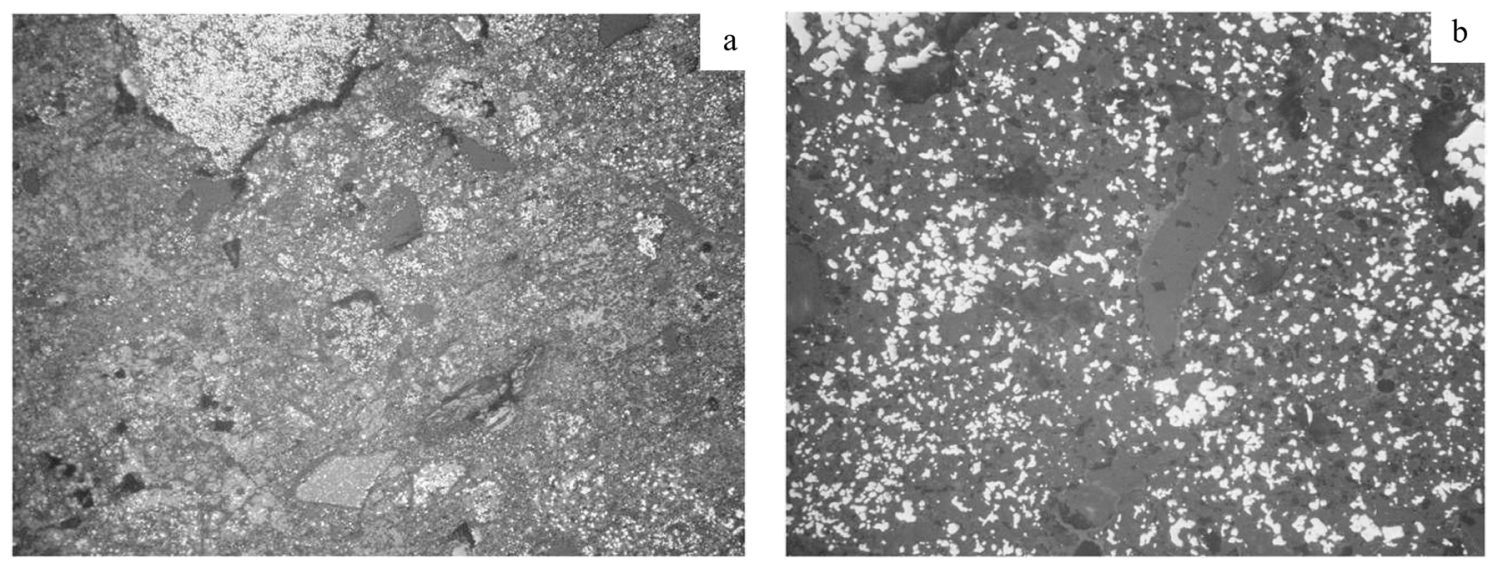

Figure 3. Optical microscope images for iron ore samples reduced at different reduction conditions a) Top zone b) Thermal reserve zone. $(x=200)$
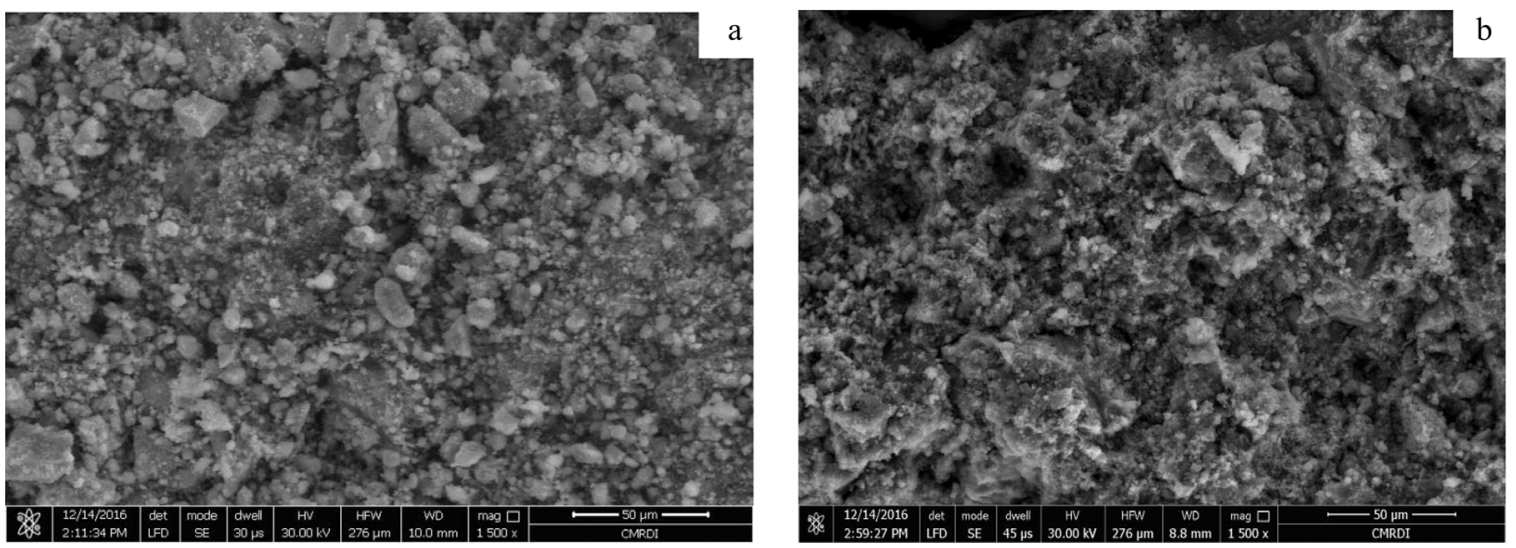

Figure 4. FESEM images for a) Green sample b) Reduced sample at top zone conditions.

\subsection{Investigation of the firing effect on reduction behavior of iron ore}

$\mathrm{X}$-ray diffraction analysis was carried out for the samples after firing and the crystalline size can be calculated from Scherrer formula:

$$
D_{p}=(0.94 \times \lambda) /(\beta \times \operatorname{Cos} \Theta)
$$

Where, $D_{\mathrm{P}}=$ Average Crystalline size, $\beta=$ Line broadening in radians, $\Theta=$ Bragg angle, $\lambda=X$-Ray wavelength

$t$ can be noticed that the iron ore mainly contains hematite phases with crystalline size 65-121 nm (goethite phase disappeared) beside some impurities such as quartz and Mn-silicate composite as shown in Fig. 5.

\subsection{Studying the reduction behavior of fired iron ore}

The isothermal reduction curves of fired briquettes reduced by different compositions of gas mixture simulating different parts of the blast furnace are given in Fig. 6. For each single

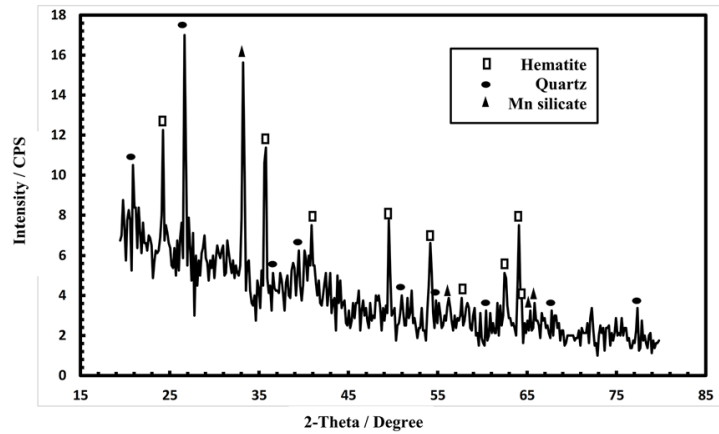

Figure 5. XRD patterns of fired iron ore samples.

reduction curve, the rate of reduction was highest at the early stages and decreased as reduction proceeds till the end of reduction. Cohesive zone and thermal reserve zone curves are almost congruent and reached 95\% after $120 \mathrm{~min}$. But for top zone conditions, the reduction extent reached $75 \%$ after 235 min which was confirmed by XRD chart in which magnetite phase appeared with metallic iron beside some quartz as impurities as shown in Fig 7. 


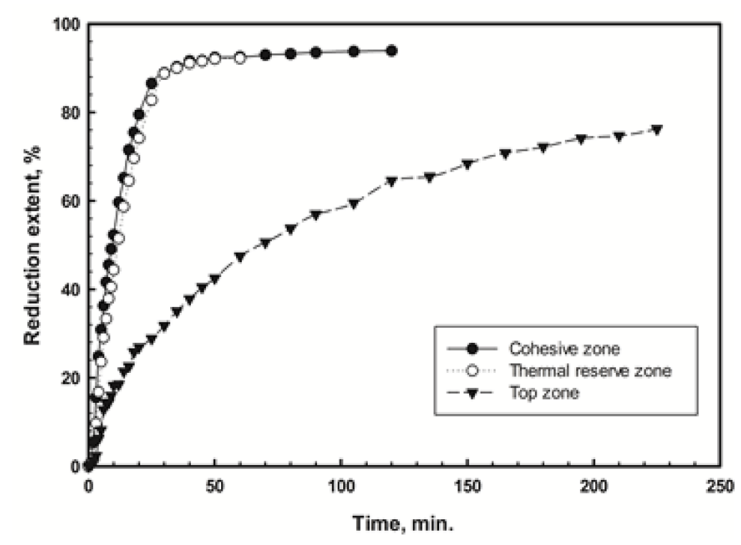

Figure 6. Reduction behavior of fired iron ore compacts at different zones of blast furnace.

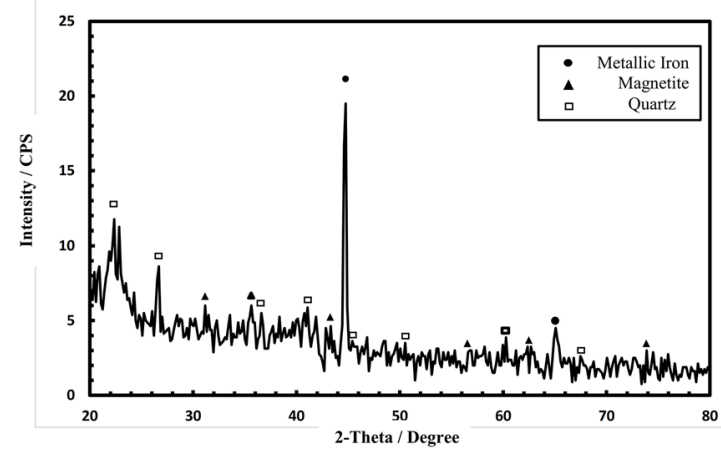

Figure 7. XRD of fired iron ore compacts reduced at top zone conditions.

Figure $8(a, b)$ shows the microstructure of the fired samples after and before reduction at top zone conditions. It can be observed that grains with size (2-4) $\mu \mathrm{m}$ were sticked as a result of firing effect for fired sample. For reduced samples, grains are impinged on each other and started to connect showing relatively higher porosity.
On the other hand, the microstructure of fired samples after and before reduction at cohesive zone conditions was examined by FESEM as shown in Fig. $9(\mathrm{a}, \mathrm{b})$. After reduction as a result of elevated reduction temperature, grain growth occurred and small spherical grains of fired samples were semi-melted together forming sintered clusters. Micro-pores between grains in fired samples started to disappear creating larger macro-pores around the clusters.

\subsection{Comparative reduction behavior between green and fired compacts at different reduction conditions}

The comparative reduction behavior at cohesive zone reduction conditions is shown in Fig. 10a for fired samples. The reduction curves of green and fired samples are almost congruent due to high temperature and reduction power at this zone. So, the effect of firing can hardly be distinguished.

By examination the microstructure of green and fired briquettes reduced at cohesive zone conditions Fig 11(a, b), grains are semi-melted and connected to each other forming spongy structure. On the other hand, fired samples only have fibrous structure at the grain surface. This spongy structure facilitates reducing gas diffusion and reduction process completion.

The comparative reduction behavior at thermal reserve zone and top zone reduction conditions is shown in Fig. 10 $(b, c)$ for green and fired briquettes respectively. Reduction rate for both curves are the same till $40 \%$ and $30 \%$ for thermal reserve zone and top zone respectively. Then, the reduction rate of fired samples became greater than green ones with higher difference in case of top zone condition.

The microstructure of green and fired samples reduced at top zone conditions was examined. For green samples, particles of different grain sizes are shown throughout the sample together with few number of macro- and micro-pores. On the other hand for fired samples, grains started to connect
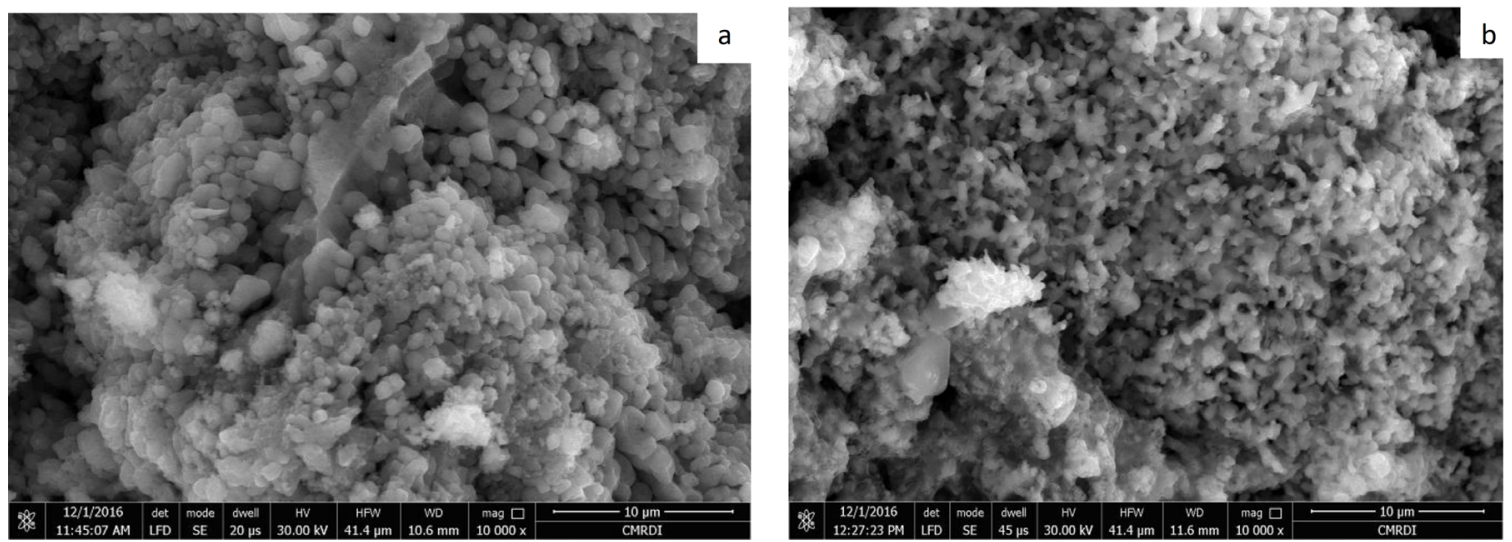

Figure 8. FESEM images for iron ore compacts: a) Fired b) Reduced at top zone conditions. 

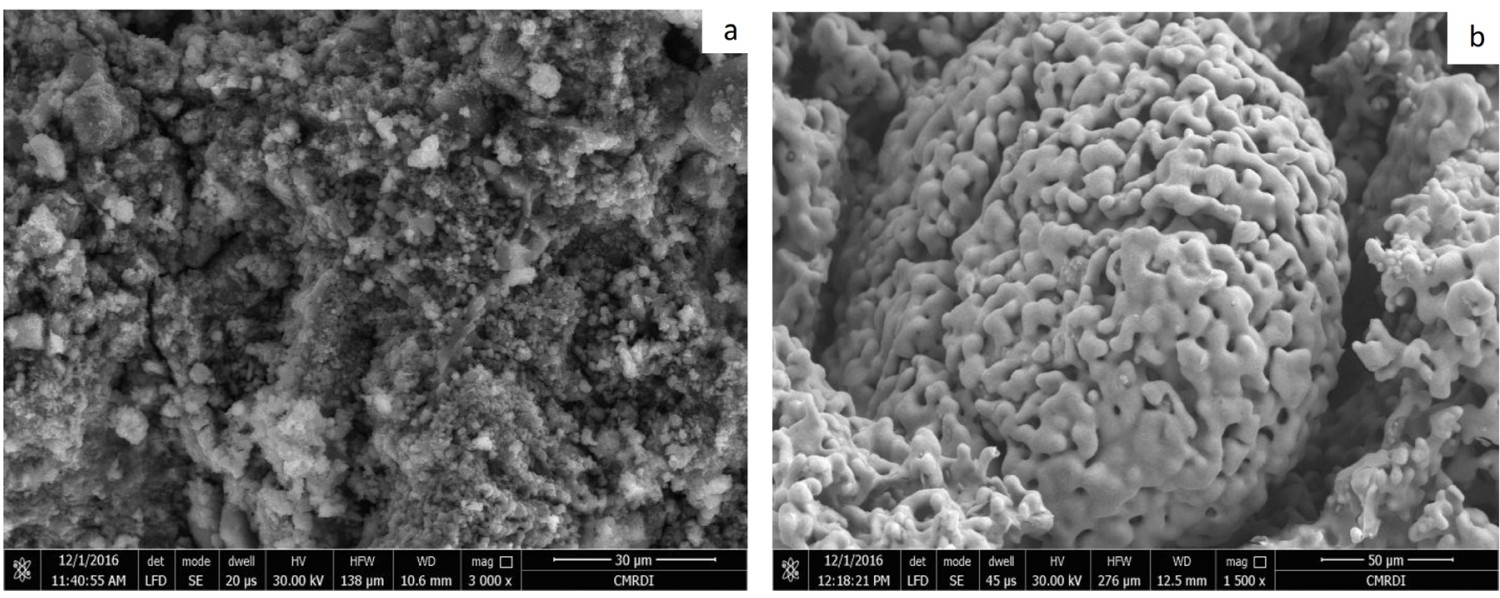

Figure 9. FESEM images for iron ore compacts: a) Fired b) Reduced at cohesive zone conditions.
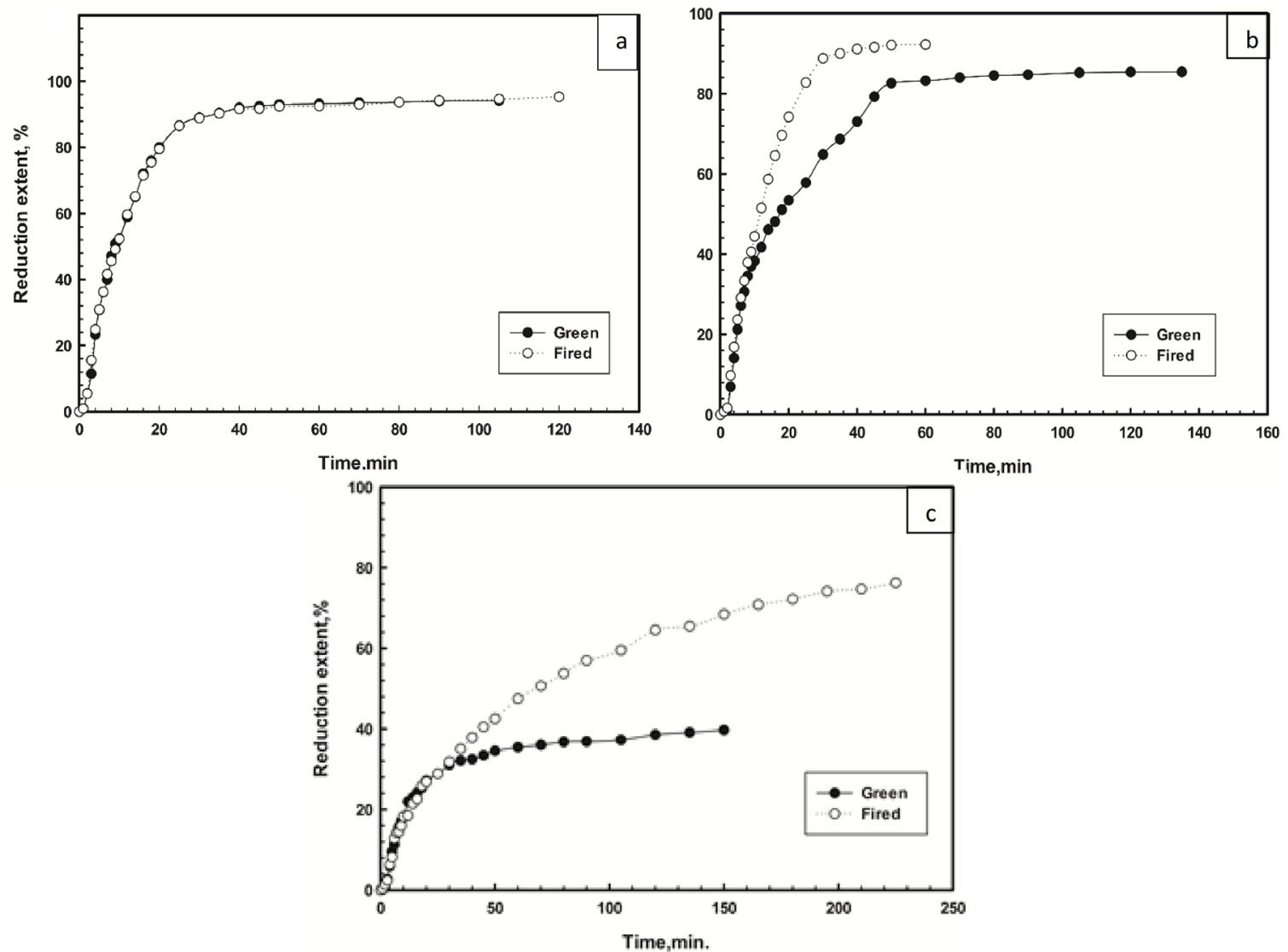

Figure 10. Reduction behavior of fired samples at different conditions: a) cohesive zone b) Thermal reserve zone c) Top zone.

with each other developing many macro- and micro-pores inside the structure which facilitate reduction process. So, the reduction rate of fired samples is greater than that for unfired ones as shown in Fig. 12 (a, b) respectively.

This phenomenon can be demonstrated as at initial reduction stages while the samples structure was porous, chemical reaction was the rate controlling step. So, the effect of firing was indistinguishable. However in case of middle and later reduction extent, reducing gases can be hardly penetrated to inner grains. Thus firing effect role began to differentiate the curves. This is an indication that firing of samples is favoured at middle and later reduction extents. 

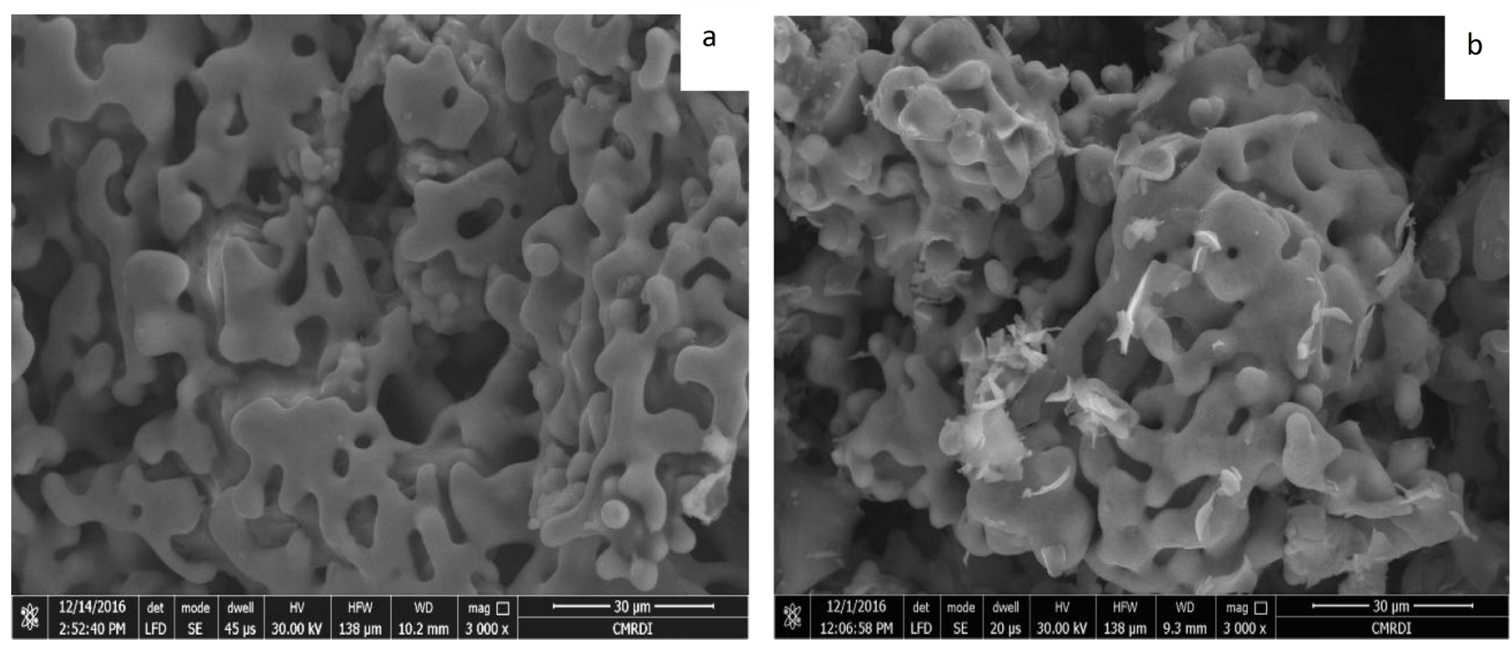

Figure 11. FESEM images for samples reduced at cohesive zone conditions: a) Green sample b) Fired sample.
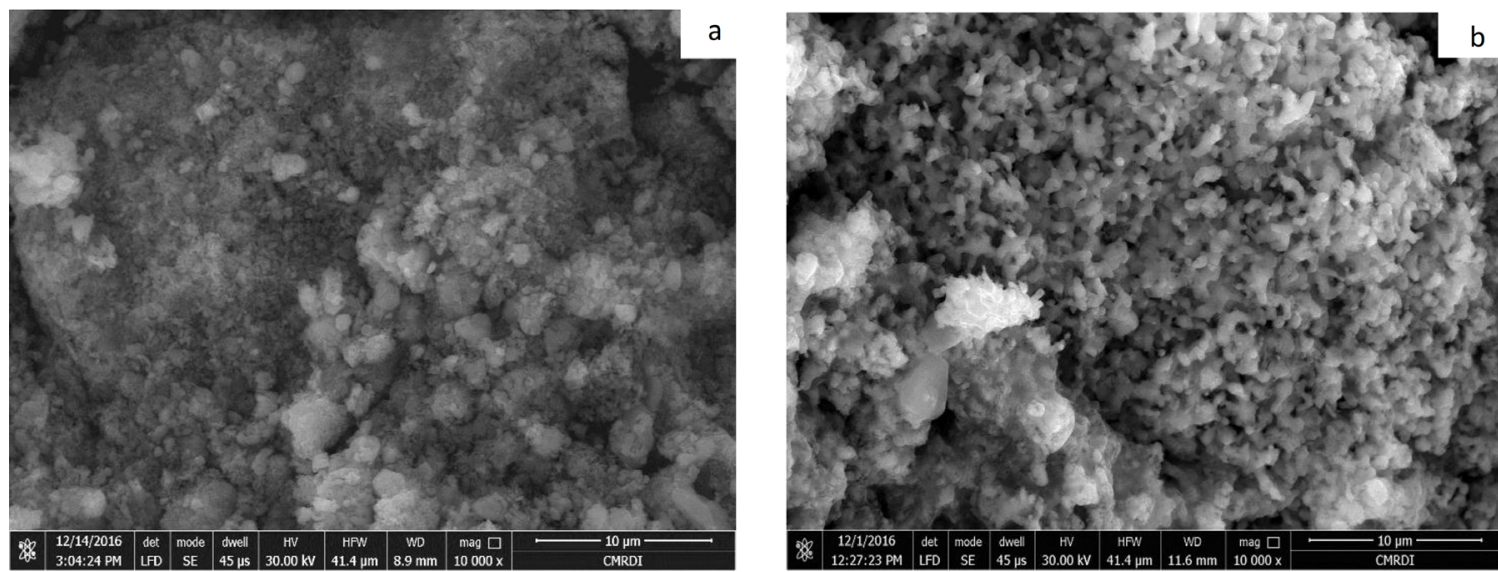

Figure 12. FESEM images for iron ore reduced at top zone conditions: a) Green sample b) Fired sample.

\section{Conclusion}

- The iron ore from El-Gedida region was isothermally reduced by different ratios of $\mathrm{H}_{2} / \mathrm{CO} / \mathrm{CO}_{2} / \mathrm{N}_{2}$ which closely represent the temperature and the theoretical composition of gas mixture at different zones of blast furnace. Samples were fired at $1000^{\circ} \mathrm{C}$ for 3 hours then isothermally reduced by the same reduction conditions.

- Samples mainly contains goethite, hematite, quartz and $\mathrm{Mn}-\mathrm{Fe}$ silicate with total iron percent 55.3\% while after firing goethite disappeared and Mnsilicate is formed.

- Reduction behavior is arranged as: (cohesive>thermal reserve>top) zones due to reduction power of different zones which affect the microstructure of reduced samples.
- As a result of slow reaction at top conditions, reducing gas created tracks within the samples which increase porosity. On the other hand at cohesive conditions, grain growth occurred and small spherical grains of fired samples were semimelted forming sintered clusters.

- The comparative reduction behavior for green and fired briquettes was demonstrated. The reduction curves of green and fired samples reduced at cohesive zone conditions are almost congruent due to high reduction power at this zone. So, the effect of firing can be hardly distinguished. But the reduction rate of fired samples is greater than that for green samples. This phenomenon is explained by morphological examination of samples. 


\section{Reference}

1. Matsui Y, Sawayama M, Kasai A, Yamagata Y, Noma F. Reduction Behavior of Carbon Composite Iron Ore Hot Briquette in Shaft Furnace and Scope on Blast Furnace Performance Reinforcement. ISIJ International. 2003;43(12):1904-1912.

2. Kumar M, Jena S, Patel SK. Characterization of properties and reduction behavior of iron ores for application in sponge ironmaking. Mineral Processing and Extractive Metallurgy Review. 2007;29(2):118-129.

3. El- Geassy AA, Nasr MI, Yousef MA, Khedr MH, Bahgat M. Behaviour of manganese oxides during magnetising reduction of Baharia iron ore by $\mathrm{CO}-\mathrm{CO}_{2}$ gas mixture. Ironmaking and Steelmaking. 2000;27(2):117-122.

4. Mousa EA, Babich A, Senk D. Reduction Behavior of Iron Ore Pellets with Simulated Coke Oven Gas and Natural Gas. Steel Research international. 2013;84(11):1085-1097.

5. Diemer P, Lungen HB, Reinke M. Utilization of coke oven gas for the production of DRI. In: Proceedings of METEC InSteelCon ${ }^{\circledR} 2011,6^{\text {th }}$ European Coke and Ironmaking Congress; 2011 Jun 27-Jul 1; Düsseldorf, Germany.

6. Bahgat M, Abdel Halim KS, El-kelesh HA, Nasr MI. Journal of Metallurgical Engineering. 2012. (ME).1 (1): 14.

7. Prakash S. Reduction and sintering of fluxed iron ore pellets - a comprehensive review. The Journal of the South African Institute of Mining and Metallurgy. 1996;96(1):3-16.
8. Hashem MN, Salah BA, El-Hussiny NA, Sayed SA, Khalifa MG, Shalabi MEMH, et al. Reduction Kinetics of Egyptian Iron Ore by Non Coking Coal. International Journal of Scientific \& Engineering Research. 2015;6(3):846-852.

9. Babich A, Senk D. Coal Use in Iron and Steel Metallurgy. In: Osborne D, ed. The Coal Handbook: Towards Cleaner Production. Cambridge: Woodhead Publishing; 2013.

10. Bahgat M, Abdel Halim KS, El-Kelesh HA, Nasr MI. Behaviour of wüstite prepared from Baharia iron ore sinter during reduction with $\mathrm{CO}-\mathrm{CO}_{2}-\mathrm{N}_{2}$ gas mixture. Mineral Processing and Extractive Metallurgy - Transactions of the Institutions of Mining and Metallurgy: Section C. 2011;120(2):102-110.

11. Li J, Wang P, Zhou L, Cheng M. The Reduction of Wustite with High Oxygen Enrichment and High Injection of Hydrogenous Fuel. ISIJ International. 2007;47(8):1097-1101.

12. Peacey JG, Davenport WG. The Iron Blast Furnace - Theory and Practice. Oxford: Pergamon Press; 1979.

13. El-Geassy AA, Shehat KA, Ezz SY. Mechanism of Iron Oxide Reduction with Hydrogen/Carbon Monoxide Mixtures. Transactions of the Iron and Steel Institute of Japan. 1977;17(11):629-635.

14. El-Geassy AA. Influence of doping with $\mathrm{CaO}$ and/or $\mathrm{MgO}$ on stepwise reduction of pure hematite compacts. Ironmaking \& Steelmaking. 1999;26(1):41-52.

15. El-Geassy AA. Reduction of $\mathrm{CaO}$ and/or $\mathrm{MgO}$-doped $\mathrm{Fe}_{2} \mathrm{O}_{3}$ Compacts with Carbonmonoxide at 1173-1473 K. ISIJ International. 1996;36(11):1344-1353. 